\title{
Homofobia e interseccionalidade: sentidos condensados a partir de uma pesquisa bibliográfica
}

\author{
SILVA, Dhones Stalbert Nunes ${ }^{1}$ \\ MIRANDA, Marcelo Henrique Gonçalves de ${ }^{2}$ \\ SANTOS, Maria do Carmo Gonçalo ${ }^{3}$
}

\section{RESUMO}

Atualmente, diante de um crescimento neoconservador e neoliberal, as práticas homofóbicas se tornaram mais frequentes e evidenciadas, sobretudo, quando se tem outros marcadores de subalternidades como gênero, classe, raça, dentre outros. Tais interseccionalidades trazem relações de poder que reproduzem violências, exclusões e desigualdades sociais. A partir desse contexto, torna-se necessário analisar os sentidos veiculados em textos de produções teóricas abordados em uma disciplina de formação continuada de docentes. Assim, temse como objetivo geral analisar os sentidos condensados sobre a homofobia e suas relações com as interseccionalidades, contidos em textos teóricoepistemológicos, em uma disciplina da Pós-Graduação stricto sensu, na área de educação em Pernambuco. Dessa maneira, a pesquisa é qualitativa e foi realizada a partir da pesquisa documental e bibliográfica. Como resultados foi constatado que os quatro textos partem de uma perspectiva construtivista ou desconstrutivista. $\mathrm{E}$ que três deles estabelecem relações entre homofobia, lesbofobia e sinaliza para interseccionalidades entre gênero, classe e raça. Entretanto, sublinha-se que é necessária a ampliação dessas interseccionalidades com a homofobia e lesbofobia, como campo de saber, visto que permitirá que os estudantes desconstruam sentidos naturalizados e essencialistas que categorizam indivíduos como corpos abjetos.

Homofobia. Interseccionalidade. Abordagens teóricas.

\section{Homophobia and intersectionality: condensed meanings from a bibliographic research}

\section{ABSTRACT}

\footnotetext{
${ }^{1}$ Mestrando do Programa de Pós-Graduação em Educação Contemporânea (PPGDUC/UFPE). E-mail: psicologo.dhones@outlook.com. Lattes: http://lattes.cnpq.br/0822620333119190. ORCID: https://orcid.org/0000-0003-3133-6933.

2 Doutor em Sociologia pelo PPGS/UFPE. Professor da Pós-Graduação em Educação Contemporânea (PPGEDUC/UFPE) e da Pós-Graduação em Direitos Humanos (PPGDH/UFPE). E-mail: mm.marcelohenrique@yahoo.com.br. Lattes: http://lattes.cnpq.br/0515157502980112. ORCID: https://orcid.org/0000-0001-9805-4792. ${ }_{3}^{3}$ Doutora em Educação pelo Núcleo de Formação de Professores e Prática Pedagógica, UFPE (2016), E-mail: mcarmouufpe@yahoo.com. Lattes: http://lattes.cnpq.br/0892001190378231. ORCID: https://orcid.org/0000-0002-5760-6009.
}

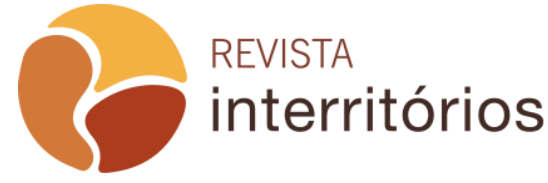

Interritórios | Revista de Educação Universidade Federal de Pernambuco, Caruaru, BRASIL | V.6 N.10 [2020] 
Currently, in face of a neoconservative and a neoliberal growing wave, homophobic practices have become more common and are shown especially when there are other markers of subalternities such as gender, class, race, among others. Such intersections bring power relations that reproduce violence, exclusions and social inequalities. From this context, it is necessary to analyze the meanings conveyed in texts of theoretical productions addressed in a discipline of continuing education for teachers. Thus, the general goal is to analyze the condensed meanings about homophobia and its relations with the intersectionality, contained in theoretical-epistemological texts in a graduation course, in the area of education in Pernambuco. In this way, it is qualitative and was carried out based on documentary and bibliographic research. As a result, it was found that the four texts start from a constructivist or deconstructivist perspective. And that three of them establish relationships between homophobia, lesbophobia signals for intersectionality among gender, class and race. However, it is emphasized that it is necessary to expand these intersectionalities with homophobia and lesbophobia as a field of knowledge since it will allow students to deconstruct naturalized and essentialist senses that categorize individuals as abject bodies.

Homophobia. Intersectionality. Theoretical approaches.

\section{Homofobia e interseccionalidad: sentidos condensados de una búsqueda bibliográfica}

\section{RESUMEN}

Actualmente, frente al crecimiento neoconservador y neoliberal, las prácticas homofóbicas se han vuelto más frecuentes y evidentes, especialmente cuando hay otros marcadores de subalternidades como el género, la clase, la raza, entre otros. Tal interseccionalidad trae relaciones de poder que reproducen violencia, exclusiones y desigualdades sociales. Desde este contexto, es necesario analizar los significados transmitidos en textos de producciones teóricas abordadas en una disciplina de educación continua para docentes. Por lo tanto, el objetivo general es analizar los significados condensados sobre la homofobia y sus relaciones con las interseccionalidades, contenidos en textos teóricoepistemológicos, en una disciplina de Post-Graduación stricto sensu, en el área de la educación en Pernambuco. De esta forma, el estudio es cualitativo y se realizó en base a la investigación documental y bibliográfica. Como resultado, se encontró que los cuatro textos comienzan desde una perspectiva constructivista o deconstructivista. $Y$ que tres de ellos establecen relaciones entre homofobia, lesbofobia y muestran señales con la interseccionalidad entre género, clase y raza. Sin embargo, se enfatiza que es necesario expandir estas interseccionalidades con la homofobia y la lesbofobia, como un campo de conocimiento, ya que permitirá a los estudiantes deconstruir los sentidos 
naturalizados y esencialistas que categorizan a los individuos como cuerpos abyectos.

Homofobia. Interseccionalidad. Enfoques teóricos.

\section{Omofobia e intersezionalitá: sensi condensati da una ricerca bibliografica}

\section{SINTESE}

Attualmente, di fronte alla crescita neoconservativa e neoliberale, le pratiche omofobe sono diventate più frequenti ed evidenti, specialmente quando ci sono altri marcatori di subalternità come genere, classe, razza, tra gli altri. Tale intersezionalità porta relazioni di potere che riproducono violenza, esclusioni e disuguaglianze sociali. Da questo contesto, è necessario analizzare i significati trasmessi nei testi delle produzioni teoriche affrontati in una disciplina di formazione continua per gli insegnanti. Pertanto, l'obiettivo generale è quello di analizzare i significati condensati sull'omofobia e le sue relazioni con le intersezionalità, contenuti nei testi teorico-epistemologici, in una disciplina di Stricto sensu post-laurea, nell'area dell'educazione a Pernambuco. In questo modo la ricerca è qualitativa ed è stata condotta sulla base di ricerche documentarie e bibliografiche. Di conseguenza, si è scoperto che i quattro testi partono da una prospettiva costruttivista o decostruttivista. E che tre di loro stabiliscono relazioni tra omofobia, lesbofobia e segnali di intersezionalità tra genere, classe e razza. Tuttavia, si sottolinea che è necessario espandere queste intersezioni con l'omofobia e la lesbofobia, come campo di conoscenza, poiché consentirà agli studenti di decostruire i sensi naturalizzati ed essenzialisti che categorizzano gli individui come corpi abietti.

Omofobia. Intersezionalità. Approcci teorici.

\section{INTRODUÇÃO}

Ao olharmos para os fenômenos sociais, precisamos superar as análises que não problematizam a naturalização de verdades absolutas nem aprofundam a sua compreensão. Inúmeras vezes, incorremos no erro de analisar os acontecimentos do cotidiano desprovidos e desvinculados da compreensão dos sentidos que são produzidos em decorrência dos contextos histórico, econômico e sociocultural. Essa prática de análise implica, geralmente, na produção de um conhecimento superficial e que (re)produz o lugar privilegiado de grupos hegemônicos que pouco contribuem para o desenvolvimento de um campo de saber comprometido com a equidade social e o combate a exclusões de gênero, raça-etnia, classe, regionalidade e ou sexualidade. Essa situação nos impede de chegarmos a outras compreensões que desestabilizam categorias naturalizadas 
e que possam desconstruir as ilusões de verdades absolutas na inteligibilidade social (MIRANDA, 2016; MIRANDA; LIMA, 2019).

Infelizmente, na sociedade contemporânea, presenciamos cada vez mais o crescimento e recrudescimento de atitudes homofóbicas, ou seja, do ódio contra sexualidades que não se adequam ao padrão da heterossexualidade compulsória ou da heteronormatividade. A partir desse contexto, indaga-se: as pessoas que interseccionam etnia-raça, gênero, classe social e sexualidade estão mais propensas a sofrerem homofobia e a sofrerem de uma forma ainda mais violenta? De que maneira se pode enfrentar a situação e ou ainda resistir, com diminuição de danos, a atitudes homofóbicas? Considerando os questionamentos acimas mencionados, tem-se como problema de pesquisa: quais os sentidos condensados sobre a homofobia e suas relações com a interseccionalidade, contidos em textos teórico-epistemológicos em uma disciplina da Pós-Graduação stricto sensu, na área de educação em Pernambuco? Vale ressaltar que o processo de formação continuada, como as pós-graduações, tem a finalidade de um aprofundamento teórico e metodológico na formação dos profissionais e pode também fomentar uma prática ética e cidadã no fortalecimento de uma sociedade mais democrática que respeite e aprenda com as diferenças.

A partir do exposto, o artigo tem como objetivo geral: analisar os sentidos condensados sobre a homofobia e suas relações com as interseccionalidades contidos em textos teórico-epistemológicos em uma disciplina da PósGraduação stricto sensu, na área de educação em Pernambuco. E como objetivos específicos: a) enumerar os referenciais teóricos contidos nos textos analisados; b) identificar as abordagens sobre a homofobia veiculados nos referidos textos; e c) mapear as possíveis relações interseccionais (classe social, gênero, etnia-raça, regionalidade etc.) com a homofobia abordadas no referencial teórico.

\section{Condensações de sentidos sobre a homossexualidade e seus desdobramentos em relação à homofobia}

Em decorrência de formações discursivas entre religião e ciência (BUTLER, 2003, 2008; FOUCAULT, 2004, 2007; BORRILLO, 2010; MIRANDA, 2011; MIRANDA; ALENCAR, 2016) que condensam sentidos sobre a sexualidade, somos socializados em um processo de inteligibilidade social que categoriza a homossexualidade, equivocadamente, como sendo anormal, pecaminosa. Além disso, esses casais são tidos como uma forma estéril de existência pelo fato do casal não conseguir conceber filhos por ambos serem do mesmo gênero. Assim, essa forma de vivenciar a sexualidade para essa 
concepção é um dos maiores pecados contra uma suposta ontologia que essencializa a "natureza" humana (BUTLER, 2003, 2008; FOUCAULT, 2007; BORRILLO, 2010).

Alguns teóricos (FOUCAULT, 2007; BORRILLO, 2010) afirmam que, antes da época moderna, na civilização grega e romana era natural que homens tivessem relação sexual com outros homens. Porém, essa relação era demarcada pela virilidade por aquele que assumia o papel ativo durante 0 intercurso sexual. $O$ fato de ser passivo ou ativo durante a relação sexual determinaria o acesso ao poder e qual posição social o indivíduo poderia assumir. O sistema judaico-cristão institui uma nova dicotomia centrada na heterossexualidade versus homossexualidade, que servirá de base para a dominação masculina e para o patriarcado. Esse arcabouço relacional acaba embasando a vida social e subjetiva, determinando os sentidos de "normalidade" e "anormalidade" sobre os corpos generificados, as identidades e as práticas sexuais.

Nesse sentido, os fundamentos Judaico-cristãos privilegiam a heterossexualidade como a única forma "normal" de vivenciar a sexualidade ao mesmo tempo em que subalterniza quaisquer outras vivências sexuais. Borrillo (2010, p. 48) afirma que "o cristianismo inaugurou, no Ocidente, uma época de homofobia totalmente nova, que ainda não havia sido praticada por outra civilização". Através dos fundamentos Judaico-cristãos, que foram disseminados no Império Romano, o Imperador Teodósio I determinou o extermínio de todos os homossexuais passivos, condenados a queimar na fogueira. Essa decisão se baseava na compreensão de que esses sujeitos eram uma ameaça para aquela civilização por colocar em risco a sobrevivência da espécie humana.

Países como Estados Unidos e França já utilizaram os fundamentos dos textos bíblicos, precisamente aqueles do livro de Levítico, que falam sobre a condenação das práticas homossexuais para embasar decisões contra a, então, denominada sodomia. Dessa forma, na compreensão da homofobia na atualidade, percebe-se como há uma condensação de sentidos em que as concepções judaico-cristãs engendram a inteligibilidade social. Essa forma de compreensão acerca da homossexualidade perpassa os diferentes espaços, respaldando e naturalizando práticas e posturas violentas, avessas a outros modos de vivenciar o desejo e a sexualidade que diferem daquela legitimada pelos livros sagrados (FOUCAULT, 2007; BORRILLO, 2010), geralmente, a partir de uma análise que não considera a construção de sentidos em contextos históricos.

Nesse percurso, após a Peste Bubônica, conhecida como "Peste Negra", que ocorreu nos anos de 1348 a 1350 na Europa, os homossexuais passaram a ser caçados e queimados na fogueira pela simples justificativa que estes impediam o repovoamento, visto que populações foram dizimadas pela doença. 
É durante os séculos XIII a XV que as perseguições se acentuam em diversas regiões, sempre embasada por decretos que criminalizavam as práticas sexuais entre pessoas do mesmo sexo, ou seja, o que vem a ser categorizado, no século $\mathrm{XIX}$, como homossexualidade. Tais decretos condenavam à morte pelo fogo, aqueles que tinham relações sexuais com pessoas do mesmo gênero, já que suas experiências sexuais eram comparadas aos sodomitas, ou seja, àqueles e àquelas que realizavam relação anal (BORRILLO, 2010). Vale ressaltar que a invenção da homossexualidade como anormalidade e pecado só tem seu sentido condensado no final do século XIX a partir da formação de vários discursos tais como exemplo o religioso e o médico (FOUCAULT, 1997; BUTLER, 2003; MIRANDA, 2011)

O poder canônico da Igreja, durante séculos, assumiu este papel de criminalizar as vivências, atualmente denominadas, de homossexuais. Tal procedimento é seguido, na primeira metade do século XX pelo Estado francês que, em 1942, seu Código Penal passa a compreender a homossexualidade como delito. Dessa forma, as vivências entre pessoas do mesmo gênero deixam de ser compreendidas apenas como pecado e passam a ser crimes puníveis, através da lei laica. Também assume sentidos de doença, com o endosso de instituições médicas. Nesse caso, a heterossexualidade assume o status de normal, a partir da ficção da homossexualidade como doença, anormalidade. Assim, tal condensação de sentidos é constituída pelos discursos religioso, médico e do Estado (FOUCAULT, 1997).

Ainda hoje, o argumento utilizado para a não aprovação dos direitos relacionados aos LGBT nos diversos congressos ou tribunais que se opõem, é conclamar a ordem natural, ou seja, a um fundamento essencialista como justificativa dessa expropriação de direitos. Dessa forma, percebemos como os preceitos religiosos ainda direcionam diversas experiências sociais na atualidade.

No Brasil, estamos acompanhando como um discurso essencialista, fundamentalista e extremamente conservador, que viola os direitos humanos e a capacidade de aprendizado com as diferenças, em uma sociedade democrática vem determinar e legitimar a abstinência sexual antes do casamento hétero; ao mesmo tempo que coloca a homossexualidade como anormalidade, com base em um pânico moral. Vale ressaltar que tais discursos fundamentalistas defendem a abstinência sexual como sendo uma política pública de prevenção de infecções sexualmente transmissíveis além de reforçar a exclusão e o suposto caráter de pecador da população LGBT. Tais processos de exclusão ganham contornos ainda mais cruéis ao interseccionarem classe social, etnia-raça, geração, regionalidade dentre outros aspectos (LUZ, 2011; ALBUQUERQUE JUNIOR, 2013; MIRANDA; LIMA, 2019). 
O conceito de interseccionalidade, inspirado no feminismo negro dos anos de 1970, enquanto interdependência das relações de poder que atravessam raça, sexo e classe, como denúncia Daves (2016); também como uma proposta para lidar com as "múltiplas fontes de identidade", evidencia a não hierarquização das formas de opressão (HIRATA, 2014). Nesse percurso, a interseccionalidade:

Sugere que, na verdade, nem sempre lidamos com grupos distintos de pessoas e sim com grupos sobrepostos. Assim, (...) ao sobrepormos o grupo das mulheres com o das pessoas negras, o das pessoas pobres e também o das mulheres que sofrem discriminação por conta da sua idade ou por serem portadoras de alguma deficiência, vemos que as que se encontram no centro - e acredito que isso não ocorre por acaso - são as mulheres de pele mais escura e também as que tendem a ser as mais excluídas das práticas tradicionais de direitos civis e humanos (CRENSHAW, 2004, p. 10).

Assim, com o cuidado de considerar as demandas, especificidades e frentes de luta de cada grupo/movimento, possibilita o suporte teóricometodológico para o enfrentamento da aliança estrutural entre racismo, patriarcado e capitalismo (MEMMI, 1989; FANON, 2008; AKOTIRENE, 2019). Nessa perspectiva,

Articulação das clivagens identitárias, repetidas vezes reposicionadas pelos negros, mulheres, deficientes, para finalmente defender a identidade política contra a matriz de opressão colonialista, que sobrevive graças às engrenagens do racismo cisheteropatriarcal capitalista (...). A interseccionalidade nos permite partir da avenida estruturada pelo racismo, capitalismo e cisheteropatriarcado, em seus múltiplos trânsitos, para revelar quais são as pessoas realmente acidentadas pela matriz de opressões (AKOTIRENE, 2019, p. 45-47).

Por sua vez, os estudos queer contribuem para a compreensão da interseccionalidade, ao tratar das diferenças de corpo, de gênero e de sexualidade, evidenciando a relação entre as diversas formas de opressão (MISKOLCI, 2007) sendo a homofobia uma delas.

A homofobia é tratada por Borrillo (2010) em sua dimensão psicológica e social que se articulam. A homofobia psicológica diz da aversão à pessoa do homossexual, enquanto a homofobia social trata da rejeição à relação de desejo entre pessoas do mesmo gênero.

Muitas vezes parece que existe em nós um homofóbico "no armário", como se esse temor que temos frente às demonstrações de afeto por pessoas do mesmo sexo fosse inerente a nossa

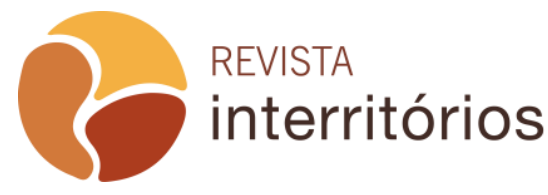

Interritórios | Revista de Educação

Universidade Federal de Pernambuco, Caruaru, BRASIL | V.6 N.10 [2020] 
identidade. Borrillo (2010, p. 87), afirma que "homofobia parece ser necessária à constituição da identidade de cada indivíduo. Ela está tão arraigada na educação que, para superá-la, impõe-se um verdadeiro exercício de desconstrução de nossas categorias cognitivas". Para ele, existem dois tipos de homofobia: a individual que se expressa pela rejeição e a social que se evidencia pela supremacia heterossexual difundida na sociedade.

Durante o processo de socialização masculina diversos aspectos são internalizados pelos homens. Os "ritos de masculinidade" nos espaços escolares, por exemplo, revelam as violências empreendidas e sofridas pelos meninos para "provar" a masculinidade hegemônica. Nesses ritos, interseccionam-se questões de gênero, classe e raça, uma vez que as violências são intensificadas em meninos considerados mais "frágeis", que não correspondem a um modelo de virilidade, com pele mais negra e mais pobres (LUZ, 2011; SANTOS, 2016). As construções de gênero impostas aos meninos cobram deles comportamentos como: não devem demonstrar seus sentimentos, mas exercer um controle sobre eles; jamais devem deixar aparente qualquer vulnerabilidade; devem competir entre si como demonstração de força e também não podem se aproximar de homens que sejam afeminados, ao contrário, aprendem que devem odiar homossexuais. Dessa forma, carregam consigo sempre um medo de serem associados aos gays, o que põe em questão a sua sexualidade, por isso constantemente existe uma negação de qualquer característica feminina que possa comprometer a sua imagem de heterossexual. Dessa forma,

Fortalecer a homofobia é, portanto, um mecanismo essencial do caráter masculino, porque ela permite recalcar o medo enrustido do desejo homossexual. Para um homem heterossexual, confrontar-se com um homem efeminado desperta a angústia em relação às características femininas de sua própria personalidade; tanto mais que esta teve de construir-se em oposição à sensibilidade, à passividade, à vulnerabilidade e à ternura, enquanto atributos do "sexo frágil" (BORRILLO, 2010, p. 89).

No processo de definição social do que é ser gay, os homens que se definem heterossexuais acabam criando uma compreensão de que gays são aqueles que permitem-se ser penetrados, afastando dos que penetram qualquer associação com a homossexualidade. $O$ ato da penetração remete a uma passividade atribuída ao feminino, logo, se o sujeito adota um comportamento ativo na relação com outro homem acredita ele não estar traindo o seu gênero, ou seja, o processo de generificação dos corpos que é reforçado cotidianamente. E por essa razão passa a necessitar de autoafirmação, através de um menosprezo por aqueles que assumem a passividade. 
Borrillo (2010) nos leva a compreender que somos reféns da lógica cultural que nos impele a aderir cegamente a uma das posições binárias que é imposta em relação à sexualidade e ao gênero. Além de assumirmos um posicionamento, somos cobrados o tempo inteiro para estarmos alinhados com a posição assumida. Não basta ser homem ou mulher, se somos homens precisamos apresentar os atributos de força, competitividade e principalmente sentir-nos atraído por mulheres, se somos mulheres precisamos ser sensíveis, amáveis e sentir-nos atraídas apenas por homens (CONNEL, 2013). Precisamos superar a compreensão baseada na realidade supostamente biológica enquanto dispositivo regulador dos corpos (BUTLER, 2003; FOUCAULT, 2007).

É justamente a dicotomia dos sexos que suporta a ordem sexual. Podemos perceber isso também na lei quando legitimava ${ }^{4}$ apenas a união entre casais heterossexuais, pois essa é, hegemonicamente, compreendida como a única forma que possibilita "o verdadeiro encontro dos seres" devido às suas complementaridades e diferenças (MELLO, 2005; GROSSI; UZIEL; MELLO, 2007; UZIEL, 2007). Diante do exposto "a homofobia diferencialista pretende afastar os homossexuais do direito comum (em particular, o direito ao casamento), a fim de salvaguardar a supremacia normativa da heterossexualidade" (BORRILLO, 2010, p. 93 - grifo do autor).

A estratégia utilizada para justificar a hegemonia heterossexual é justamente um processo de estigmatização do outro que diverge do modelo comparativo, essa tática já se demonstrou eficiente em diversos outros processos de dominação, tais como: no racismo, na xenofobia dentre outros. Nessa perspectiva, a lente interseccional ajuda a enxergar essa tática, uma vez que a estrutura de opressão é semelhante nas clivagens identitárias (CRENSHAW, 2004; LUZ, 2011; AKOTIRENE, 2019).

Borrillo (2010) afirma que a principal estratégia de enfrentamento da homofobia deve ocorrer a partir de uma ação pedagógica que objetive a modificação da imagem da heterossexualidade como o modelo natural e da homossexualidade compreendida como desvio do modelo natural. Tal mudança pedagógica está cada vez mais difícil na atualidade da sociedade brasileira, uma vez que a gestão pública vem assumindo uma postura autoritária, fascista, racista, misógina e Igbtfóbica que viola os direitos humanos (MIRANDA; LIMA, 2019). Diante dessa realidade, a interseccionalidade além de contribuir com a análise articulada pode possibilitar o enfrentamento das diversas formas de desigualdade.

Rios (2009) em seu texto, realiza uma comparação entre as manifestações homofóbicas e outros tipos de expressões discriminatórias, tais

\footnotetext{
${ }^{4}$ A partir da Resolução no 175 de 14 de maio de 2013, foi aprovado, durante a sessão 169 do plenário do Conselho Nacional de Justiça (CNJ), o casamento civil entre pessoas do mesmo sexo, o que obrigou os cartórios e as autoridades a aceitar este tipo de união. 
como: sexismo, racismo e antissemitismo e percebe que a homofobia ainda é a expressão discriminatória mais negligenciada, já que existem leis que criminalizam o racismo, porém quando se trata de manifestações homofóbicas ele constata a existência de uma leniência.

Em comparação com outros modos de preconceito e discriminação, os estudos sobre as expressões da sexualidade ainda são muito recentes. Rios (2009, p. 59), conceitua homofobia do seguinte modo: "é a modalidade de preconceito e de discriminação direcionada contra homossexuais". Vale ressaltar que o fato do conceito de homofobia não possibilitar a visibilidade da violência sofrida também por outros grupos que expressam sua sexualidade fora dos padrões heteronormativos, fez com que surgissem diversos termos com 0 objetivo de especificar e ou ampliar a percepção da experiência violenta vivenciada, tais como: lesbofobia, transfobia e bissexualfobia ou ainda lgbtfobia.

O que impede o avanço de ações contra as práticas de homofobia é justamente o fato de existir em pleno século XXI pessoas que ainda atribuem à homossexualidade um caráter doentio, assim como subalternizam a experiência homossexual inferiorizando-a em detrimento do padrão heterossexual.

Entretanto, a homofobia é a violência contra aqueles que desejam pessoas do mesmo sexo; como também, uma agressão aos princípios democráticos que preconizam a igualdade entre todas as pessoas independente de raça, religião, sexualidade, gênero, dentre outros.

Muitos problemas psicológicos enfrentados por pessoas que são vítimas da homofobia estão fundamentados na culpabilização de si que passam a compreender que o seu desejo por pessoas do mesmo sexo é uma deficiência que eles não conseguem superar, o que acaba promovendo uma internalização da hostilidade social que levam muitos a tirarem a própria vida. O processo de enfrentamento da homofobia passa pelo questionamento e a problematização da lógica heterossexista, que propaga a hierarquia entre as sexualidades, assim como ocorreu com as raças.

Para além de legislar sobre a homofobia, criminalizando as práticas de violência contra homossexuais, destacamos a mudança de compreensão social acerca das múltiplas formas de vivenciar a sexualidade:

A educação relativa à luta contra a homofobia consistiria, afinal de contas, em sensibilizar a população heterossexual de maneira que esta deixe de considerar sua sexualidade como incontestável ou seu comportamento como necessariamente compartilhado por todos; ou seja, essa educação teria o objetivo de mostrar que outras formas de sexualidade podem coexistir com a heterossexualidade, sem que esta seja prejudicada ou venha a constituir o objeto de provocação por parte dos 
homossexuais (BORRILLO, 2010, p. 113).

O trabalho pedagógico pode contribuir para desmistificar os fantasmas associados às práticas sexuais por pessoas do mesmo sexo, bem como refletir acerca da heterossexualidade como norma, geradora de diversas formas de violência.

Louro (2009, p. 85), a partir de Foucault, propõe uma reflexão: "precisamos verdadeiramente de um verdadeiro sexo?" Essa questão se demonstra bem problematizadora por nos remeter a uma atual fixidez social imperativa de que "precisamos" de um verdadeiro sexo. Podemos perceber isso através da constante reiteração da heterossexualidade como verdade absoluta, "normal" e "natural" para as experiências sexuais.

Será que existe espaço para outras práticas sexuais possam aparecer como legitimadas para além da heterossexualidade compulsória ou da heteronormativa, enquanto outras são invisibilizadas através das relações de poder que validam o que pode ser considerado verdade e normalidade? Vale sublinhar que, "não há como negar (e todos podemos lembrar situações para comprovar isso!), que quanto menos for notada ou quanto mais for invisível uma relação de poder mais ela será eficiente" (LOURO, 2009, p. 86 - grifo da autora).

Até o século XIX as diferenças entre o corpo feminino e masculino eram compreendidas a partir de graus de perfeição, em que acreditavam ser a mulher imperfeita por seu aparelho reprodutor ser desenvolvido internamente, o que divergia do corpo masculino considerado perfeito. Quando essa concepção foi substituída pelo modelo de dois sexos opostos, promoveu-se uma nova compreensão da sexualidade na qual o corpo assume uma centralidade ao tornar-se causa e justificativa das diferenças. Nesse caminho, há o engendramento do corpo pela discursividade que é esquecida e ganha um status ontológico do ser em pares dicotômicos excludentes e hierarquizados (LAQUEUR, 2001; BUTLER, 2003, 2008; LOURO, 2009).

Vale destacar que até o final do século XIX foram homens que definiram ambos os corpos, atribuindo a eles sentidos e significados a partir do seu olhar masculino. Tais definições acabam produzindo discursos que possuem status de verdade por estarem fundamentados na ciência. A partir do olhar científico que passou a ditar o que é considerado "verdadeiro" e "normal", constrói-se um novo lugar para a homossexualidade no qual o sujeito deixa de ser aquele que cometeu apenas um pecado e passa a ser visto como alguém que pertence a outra espécie. Por esta razão, "para este tipo de sujeito, haveria que inventar e pôr em execução toda uma sequência de ações: punitivas ou recuperadoras, de reclusão ou de regeneração, de ordem jurídica, religiosa ou educativa" (LOURO, 2009, p. 88) que são endossados pelo discurso da ciência sexual que define o que é "normal" e "anormal. 
Nessa lógica, a partir de uma perspectiva do paradigma PósEstruturalista, os sentidos produzidos sobre as sexualidades "anormais" são de extrema importância para completar os sentidos sobre a denominada sexualidade "normal" (BUTLER, 2003, 2008; FOUCAULT, 2007; MIRANDA, 2011; SIQUEIRA; MIRANDA, 2018; MIRANDA; LIMA, 2019).

Dessa maneira, a primazia da heterossexualidade como "normal" adquiriu esse estatuto por meio do processo que inventou a homossexualidade como algo "anormal". Fica evidente, assim, a interdependência existente entre os dois modos de vivenciar a sexualidade, já que ser heterossexual exige a negação do oposto ao mesmo tempo em que a heterossexualidade completa o seu sentido de "normalidade" precisando colocar outras práticas sexuais como anormais, como no caso da homossexualidade. Ao assumirmos uma identidade sexual, somos interpelados a negar todas as características que excedam a ficcionalidade das categorias de heterossexualidade e de homossexualidade. Essa interpelação, reforçada cotidianamente, ocorre em diversas instâncias da nossa vida, seja na escola, na família, no Estado, na Igreja, na mídia.

A todo tempo, somos convocados a negar tudo aquilo que não é considerado "natural", pois no viés desse discurso nascemos macho ou fêmea, homem ou mulher, heterossexual ou homossexual. Tudo que exceder essas ficcionalidades das categorias dicotômicas, ou seja, estiver fora dessa teia discursiva, acaba sendo considerado aberração.

Nesse caminho, Junqueira (2009) nos convida a subverter a homofobia nos espaços escolares, que é fruto de uma teia discursiva bem mais ampla, já que na escola são reproduzidas as vivências culturais, institucionais e históricas. Se não cuidarmos desse assunto, corremos o grande risco de estar sendo coniventes com a perpetuação de violências como o sexismo, o racismo e a Igbtfobia. Conforme Santos (2016) alerta, há uma intersecção entre as formas de opressão nas escolas e, geralmente, um silenciamento por parte da prática docente em relação às violências de gênero e de sexualidade.

Junqueira (2009) sublinha a capacidade de socialização da instituição escolar que está fundamentada na reprodução de padrões sociais. Tal situação favorece a perpetuação dos diversos tipos de preconceito, discriminação, exclusões e violências: físicas, sexuais, simbólica que chegam a eliminar a vida de muitos indivíduos. Nesse caminho,

Tratamentos preconceituosos, medidas discriminatórias, ofensas, constrangimentos, ameaças e agressões físicas ou verbais têm sido uma constante na vida escolar e profissional de jovens e adultos LGBT. Essas pessoas veem-se desde cedo às voltas com uma "pedagogia do insulto", constituída de piadas, brincadeiras, jogos, apelidos, insinuações, expressões desqualificantes 
poderosos mecanismos de silenciamento e de dominação simbólica (JUNQUEIRA, 2009, p. 17).

Muitas vezes a expressão de violência contra homossexuais na escola é alimentada pela existência de uma masculinidade hegemônica que incentiva meninos a agirem de forma violenta contra aqueles que divergem do modelo padrão, só para reafirmar a sua masculinidade, pois socialmente "homem que é homem bate em veado" (JUNQUEIRA, 2009).

Assim, Viñuales (2002) afirma que somos sujeitos de desejos e a mente humana é o maior campo de batalha já que tentamos compreender as diversas formas que a sexualidade se expressa e parece que insistimos em reduzi-la a aspectos genéticos e biológicos. Esse assujeitamento do sujeito por meio da inteligibilidade heteronormativa termina contribuindo para limitar a construção e compreensão da realidade via uma lógica linear sexo-gênero-sexualidade e pares dicotômicos excludentes e hierarquizados de corpo/sexo (macho-fêmea), gênero (homem-mulher) e sexualidade (heterossexualidade-homossexualidade) (BUTLER, 2003, 2008).

Um marco importante para os homossexuais é o fato de que em 1954, Evelyn Hooker retira o estigma de doença mental que pairava sobre as experiências entre pessoas do mesmo sexo, já que esses não sentiam angústia em relação ao seu desejo e quando sentiam, esse sentimento estava relacionado ao tratamento discriminatório que recebiam da sociedade. Vale ressaltar ainda que os homossexuais não apresentam dificuldades em suas relações sociais (VIÑUALES, 2002).

Nesse caminho, o conceito de lésbica como sendo uma "pessoa que se identifica como uma mulher que ama e deseja outras mulheres" (VIÑUALES, 2002, p. 74), assim como outros modos de expressão sobre a sexualidade, a lesbianidade é construída socialmente através dos discursos sendo seu significado mutável ao longo da história da humanidade.

Vale ressaltar que as lésbicas sofrem uma violência dupla: uma por ser mulher diante de uma sociedade significativamente machista, sexista e patriarcal; e a outra, por sentir desejo por pessoas do mesmo gênero. Por essa razão precisamos tratar as diversas fobias ao invés de generalizá-las em um único termo homofobia. Assim, cada vez mais ganha espaço, eleita pelo movimento LGBT, o termo LGBTfobia, como explicitado anteriormente.

\section{Aspectos metodológicos}

A pesquisa é de natureza qualitativa por buscar ter acesso a uma compreensão dos aspectos subjetivos que

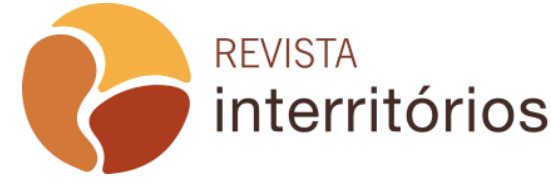

Interritórios | Revista de Educação Universidade Federal de Pernambuco, Caruaru, BRASIL | V.6 N.10 [2020] 
subjazem as produções de conhecimento sobre interseccionalidade e homofobia. Vale salientar que autores e autoras dos textos analisados estão inseridos no tempo e espaço, ou seja, são interpelados por interseccionalidade de classe, gênero, raça, sexualidade, regionalidade e geração. As autoras e os autores são ao mesmo tempo sujeitos e objetos de sua pesquisa e da produção de conhecimento nesse campo de saber entre homofobia e interseccionalidade. Nesse caminho, a nossa pesquisa qualitativa foca sua análise na compreensão da realidade social centrando-se na homofobia e suas relações com a interseccionalidade, a partir dos sentidos condensados e problematizados na produção de conhecimento trabalhada na referida disciplina do Programa de Pós-Graduação stricto sensu.

Nesse viés, o objetivo geral do artigo é analisar os sentidos condensados sobre a homofobia e suas relações com as interseccionalidades contidos em textos teórico-epistemológicos em uma disciplina da Pós-Graduação stricto sensu, na área de educação em Pernambuco. O universo da pesquisa foi composto por textos utilizados em uma turma do mestrado da referida PósGraduação. Tal disciplina possuiu uma carga horária de trinta horas/aula e foi composta por aproximadamente dezessete alunos. A referida disciplina foi ministrada por docentes que trabalham com as questões de corpo, gênero e de sexualidade e seus entrecruzamentos com raça-etnia e colonialidade.

Os encontros da disciplina foram realizados uma vez por semana, das 14:00 às 18:00 horas, com o propósito de discutir os referenciais bibliográficos propostos na ementa da disciplina. Foram realizados dez encontros que ocorreram no segundo semestre de 2019. As aulas eram expositivas e dialogadas com a utilização de slides e seu método avaliativo foi composto por seminários temáticos, realizados individualmente ou em dupla, participação nos debates e a entrega de um artigo ao final da disciplina.

Para coleta dos dados foram utilizadas a pesquisa documental e bibliográfica. Vale ressaltar que a pesquisa documental trilha caminhos semelhantes ao da pesquisa bibliográfica, sendo a principal diferença que, a pesquisa documental recorre a fontes mais difusas que geralmente não passaram por um tratamento analítico. Já o estudo bibliográfico é caracterizado da seguinte forma:

A pesquisa bibliográfica é feita a partir do levantamento de referências teóricas já analisadas, e publicadas por meios escritos e eletrônicos, como livros, artigos científicos, páginas de web sites. Qualquer trabalho científico inicia-se com uma pesquisa bibliográfica, que permite ao pesquisador conhecer 0 que já se estudou sobre o assunto. Existem, porém pesquisas científicas que se baseiam unicamente na pesquisa bibliográfica, procurando referências teóricas publicadas com o objetivo de 
recolher informações ou conhecimentos prévios sobre 0 problema a respeito do qual se procura a resposta (FONSECA apud GERHARDT; SILVEIRA, 2009, p. 37).

$\mathrm{Na}$ primeira etapa do estudo foi realizada uma análise documental da ementa, apresentada para os alunos da disciplina com o objetivo de identificar qual a proposta de abordagem da homofobia estava preconizada na ementa, assim como sua representatividade (presença ou ausência) em relação aos outros temas propostos. Em seguida, realizamos a pesquisa bibliográfica com as referências teórica-epistemológicas indicadas na ementa da disciplina, a fim de apontar as abordagens apresentadas acerca da homofobia e a sua relação com as interseccionalidades.

\section{Análise documental e bibliográfica}

Ao analisar a ementa da disciplina fica evidente que ela pretende estudar as abordagens teóricas e epistemológicas acerca dos princípios políticos e pedagógicos para uma educação não sexista. Tendo como principais pontos a serem discutidos e abordados: patriarcado, relações de gênero, Igbtfobia e as diversas concepções do feminismo.

$\mathrm{Na}$ ementa foram elencados os seguintes objetivos: a) Debater as categorias centrais para teorização e análise do feminismo, gênero e patriarcado; b) Discutir a invisibilidade da mulher na história e na ciência; c) Conhecer algumas abordagens sobre o feminismo; d) Debater a relação de gênero e educação; e) Refletir sobre as questões do estudo da diversidade sexual; f) Abordar as diferenças de gênero e de sexualidade, a partir das perspectivas dialogais e plurais, problematizando os desafios da prática pedagógica com finalidade interventiva, visando à justiça curricular.

A partir dos objetivos apresentados, percebemos o tema da homofobia contemplado no objetivo (e), quando é proposta uma reflexão sobre as questões da diversidade sexual, visto que tratar sobre esse tipo de diversidade é tratar inerentemente sobre o preconceito e a discriminação sofrida pelas pessoas que fazem parte desse grupo.

Os conteúdos propostos na ementa da disciplina foram os seguintes: A) Feminismo, Gênero e Patriarcado - teorização e categorias de análise; B) A invisibilidade da mulher na história e na ciência; C) Feminismos; D) Gênero e Educação; E) Diversidade sexual na Educação; F) Teoria Queer, diferenças e heterossexismo; G) Abordagens do Currículo e da Didática no trato às diferenças; H) Invisibilidade de gênero e de sexualidade nos currículos vividos e 
prescrito na educação; I) Diferenças de gênero e sexualidade no currículo e na prática pedagógica, na perspectiva da justiça curricular.

Diante da amplitude do campo de conhecimento sobre corpo, gênero, sexualidade, feminismos e suas interseccionalidades para serem trabalhados durante uma disciplina, na Pós-Graduação, os textos que selecionamos para análise foram essenciais nas clivagens identitárias entre homofobia, lesbofobia e interseccionalidades. Nessa perspectiva, quando analisamos os conteúdos propostos na ementa, percebemos em quatro deles uma abordagem do tema homofobia e lesbofobia. Essa constatação surgiu a partir do conteúdo $E, F, G$, I (acima mencionados), uma vez que todos propõem abordar as questões das diferenças. Assim, consideramos que os textos propostos abordam a homofobia seja de forma direta ou por meio de seus entrecruzamentos com as interseccionalidades.

O planejamento das aulas contido no plano de curso contribuiu para a compreensão do percurso teórico adotado e, ao mesmo tempo, indicar os sentidos contidos nos textos estudados como corpus de análise da pesquisa; isto é, os quatro textos sobre homofobia e lesbofobia e seus desdobramentos com as interseccionalidades. Destaca-se ainda, que a referida disciplina disponibilizou textos específicos com abordagens interseccionais, embora não tratassem especificamente desse conceito, relacionando classe, raça, gênero, colonialidade. Entretanto, nosso foco recaiu sobre os textos acerca da homofobia e lesbofobia que sublinharam as clivagens identitárias.

Tabela 1 - Planejamento das aulas

\begin{tabular}{|c|c|c|}
\hline Aulas & Conteúdo & Textos-base \\
\hline Aula 1 & $\begin{array}{l}\text { Apresentação da disciplina, conteúdos e } \\
\text { introdução ao tema. }\end{array}$ & Planejamento da Disciplina \\
\hline \multirow[t]{3}{*}{ Aula 2} & \multirow{3}{*}{$\begin{array}{l}\text { Feminismo, Gênero e Patriarcado } \\
\text { teorização e categorias de análise }\end{array}$} & $\begin{array}{l}\text { SCOTT, Joan. Gênero: uma categoria útil de análise } \\
\text { histórica. In: LOPES, Eliane Marta Teixeira; LOURO, } \\
\text { Guacira Lopes. Educação \& Realidade. V. 16, no 2, } \\
\text { jul/dez. Porto Alegre: UFRGS, } 1990 .\end{array}$ \\
\hline & & $\begin{array}{l}\text { CONNELL, R. W. Como teorizar o patriarcado? In: } \\
\text { Educação \& Realidade. V. 16, no 2, jul/dez. Porto } \\
\text { Alegre: UFRGS, } 1990 .\end{array}$ \\
\hline & & $\begin{array}{l}\text { HARDING. Sandra. A instabilidade das categorias } \\
\text { analíticas na teoria feminista. In: Revista Estudos } \\
\text { Feministas, no } 1 / 93, \text { p. 7-31. } 1993 \text {. }\end{array}$ \\
\hline Aula 3 & $\begin{array}{l}\text { A invisibilidade da mulher na história e } \\
\text { na ciência }\end{array}$ & $\begin{array}{l}\text { RAGO, Margaret. ‘Epistemologia Feminista, Gênero } \\
\text { e História'. In: Joana M. PEDRO e Miriam P. } \\
\text { GROSSI (orgs.), Masculino, Feminino, Plural. } \\
\text { Florianópolis: Editora das Mulheres, 1998, pp.: 21-42. }\end{array}$ \\
\hline
\end{tabular}


Homofobia e interseccionalidade: sentidos condensados a partir de uma pesquisa bibliográfica

\begin{tabular}{|c|c|c|}
\hline & & $\begin{array}{l}\text { COLLING, Ana Maria. A resistência da mulher na } \\
\text { ditadura militar do Brasil. Rosa dos tempos, } 1997 .\end{array}$ \\
\hline & & $\begin{array}{l}\text { HARDING, Sandra. Ciência e tecnologia no mundo } \\
\text { pós-colonial e multicultural: Questões de gênero. In: } \\
\text { Revista Labrys, no 03, jan-jul, } 2003 \text {. }\end{array}$ \\
\hline \multirow[t]{3}{*}{ Aula 4} & \multirow[t]{3}{*}{ Feminismos } & $\begin{array}{l}\text { LAGARDE, Marcela, "El género”, fragmento literal: } \\
\text { ‘La perspectiva de género. In: Género y feminismo. } \\
\text { Desarrollo humano y democracia, Ed. horas y } \\
\text { HORAS, España, 1996, pp. 13-38. }\end{array}$ \\
\hline & & $\begin{array}{l}\text { LUGONES, María. Hacia un feminismo descolonial. ; } \\
\text { In: Hypatia, vol 25, no } 4 \text {, out. } 2010 \text {. }\end{array}$ \\
\hline & & $\begin{array}{l}\text { DAVIS, ANGELA, Mulheres, Raça e Classe. São } \\
\text { Paulo, Ed. Boitempo, } 2016 \text { Cap. 1, } 2 \text { e } 3 .\end{array}$ \\
\hline \multirow[t]{3}{*}{ Aula 5} & \multirow[t]{3}{*}{ Gênero e educação } & $\begin{array}{l}\text { MEYER, Dagmar E. Estermann. Corpo, Violência e } \\
\text { Educação: uma abordagem de gênero. In: } \\
\text { JUNQUEIRA, Rogério Diniz (Org). Diversidade } \\
\text { Sexual na Educação: problematizações sobre a } \\
\text { homofobia nas escolas. Brasília: Ministério da } \\
\text { Educação, Secretaria de Educação Continuada, } \\
\text { Alfabetização e Diversidade, UNESCO, } 2009 .\end{array}$ \\
\hline & & $\begin{array}{l}\text { LOURO, Guacira Lopes. Práticas educativas } \\
\text { feministas. In: LOURO, Guacira Lopes. Gênero, } \\
\text { sexualidade e educação: uma perspectiva pós- } \\
\text { estruturalista Petrópolis, RJ: Vozes, } 1997 .\end{array}$ \\
\hline & & $\begin{array}{l}\text { RIOS, Roger Raupp. Homofobia na Perspectiva dos } \\
\text { Direitos Humanos e no Contexto dos Estudos sobre } \\
\text { Preconceito e Discriminação. In: JUNQUEIRA, } \\
\text { Rogério Diniz (Org). Diversidade Sexual na } \\
\text { Educação: problematizações sobre a homofobia nas } \\
\text { escolas. Brasília: Ministério da Educação, Secretaria } \\
\text { de Educação Continuada, Alfabetização e } \\
\text { Diversidade, UNESCO, 2009. }\end{array}$ \\
\hline \multirow[t]{3}{*}{ Aula 6} & \multirow[t]{3}{*}{ Diversidade Sexual na Escola } & $\begin{array}{l}\text { JUNQUEIRA, Rogério Diniz. Homofobia nas Escolas: } \\
\text { um problema de todos In: JUNQUEIRA, Rogério } \\
\text { Diniz (Org). Diversidade Sexual na Educação: } \\
\text { problematizações sobre a homofobia nas escolas. } \\
\text { Brasília: Ministério da Educação, Secretaria de } \\
\text { Educação Continuada, Alfabetização e Diversidade, } \\
\text { UNESCO, 2009. }\end{array}$ \\
\hline & & $\begin{array}{l}\text { VIÑUALES, Olga. Lesbofobia. Barcelona: Edicions } \\
\text { Bellaterra, } 2002 .\end{array}$ \\
\hline & & $\begin{array}{l}\text { PERES, Wiliam Siqueira. Cenas de Exclusões } \\
\text { Anunciadas: travestis, transexuais, transgêneros e a } \\
\text { escola brasileira. In: JUNQUEIRA, Rogério Diniz } \\
\text { (Org). Diversidade Sexual na Educação: } \\
\text { problematizações sobre a homofobia nas escolas. } \\
\text { Brasília: Ministério da Educação, Secretaria de }\end{array}$ \\
\hline
\end{tabular}


Homofobia e interseccionalidade:

sentidos condensados a partir de uma pesquisa bibliográfica

\begin{tabular}{|c|c|c|}
\hline & & $\begin{array}{l}\text { Educação Continuada, Alfabetização e Diversidade, } \\
\text { UNESCO, } 2009 .\end{array}$ \\
\hline \multirow[t]{3}{*}{ Auula 7} & \multirow[t]{3}{*}{$\begin{array}{l}\text { Teoria Queer, diferenças e } \\
\text { heterossexismo }\end{array}$} & $\begin{array}{l}\text { BENTO, Berenice. A reinvenção do corpo: } \\
\text { sexualidade e gênero na experiência transexual. Rio } \\
\text { de Janeiro: Garamond. } 2006 \text {. }\end{array}$ \\
\hline & & $\begin{array}{l}\text { BORRILLO, Daniel. Homofobia: História e crítica } \\
\text { de um preconceito. Belo Horizonte: Editora } \\
\text { Autêntica, 2010. }\end{array}$ \\
\hline & & $\begin{array}{l}\text { MISKOLCI, Richard. Teoria Queer: um aprendizado } \\
\text { pelas diferenças. 2. ed. Belo Horizonte: Autêntica } \\
\text { Editora: UFOP - Universidade Federal de Ouro Prefd7, } \\
2015 .\end{array}$ \\
\hline \multirow[t]{3}{*}{ Aula 8} & \multirow{3}{*}{$\begin{array}{l}\text { Cruzada moral contra gênero e } \\
\text { sexualidade }\end{array}$} & $\begin{array}{l}\text { BALIEIRO, Fernando de Figueiredo. "Não se meta } \\
\text { com meus filhos": A construção do pânico moral da } \\
\text { criança sob ameaça. In: Cadernos Pagu. no. } 53 . \\
2018 \text {. }\end{array}$ \\
\hline & & $\begin{array}{l}\text { MISKOLCI, Richard. Exorcizando um fantasma: os } \\
\text { interesses por trás do combate à "ideologia de } \\
\text { gênero". In: A construção do pânico moral da criança } \\
\text { sob ameaça. In: Cadernos Pagu. N. 53. } 2018\end{array}$ \\
\hline & & $\begin{array}{l}\text { FELIPE, Jane; GUIZZO, Bianca Salazar. Erotização } \\
\text { dos corpos infantis na sociedade de consumo. In: Pro- } \\
\text { Posições. v. 14, n. } 3 \text { (42) - set./dez. } 2003 \text {. }\end{array}$ \\
\hline \multirow{3}{*}{ Aula 9} & \multirow{3}{*}{ Currículo, gênero e sexualidade } & $\begin{array}{l}\text { TORRES SANTOMÉ, Jurjo. Currículo escolar e } \\
\text { justiça social: o cavalo de Troia da educação. } \\
\text { Tradução: Alexandre Salvaterra; revisão técnica: } \\
\text { Álvaro Hypolito. Porto Alegre: Penso, } 2013 \text {. }\end{array}$ \\
\hline & & $\begin{array}{l}\text { MACEDO, Elizabeth. O currículo no portão da escola. } \\
\text { In: MACEDO, Elizabeth; TANNIERY, Thiago (Orgs.) } \\
\text { Currículo, sexualidade a ação docente. 1.ed. } \\
\text { Petrópolis, RJ: DP et Alii, } 2017 \text {. }\end{array}$ \\
\hline & & $\begin{array}{l}\text { LOURO, Guacira Lopes. Currículo, Género e } \\
\text { sexualidade. Portugal: Porto Editora, 2000. }\end{array}$ \\
\hline \multirow[t]{2}{*}{ Aula 10} & \multirow[t]{2}{*}{$\begin{array}{l}\text { Práticas pedagógicas, gênero e } \\
\text { sexualidade }\end{array}$} & $\begin{array}{l}\text { MELLO, Luiz; GROSSI, Miriam; UZIEL, Anna Paula. A } \\
\text { escola e @s filh@s de lésbicas e gays: reflexões } \\
\text { sobre conjugalidade e parentalidade no Brasil. In: } \\
\text { JUNQUEIRA, Rogério Diniz (Org). Diversidade Sexual } \\
\text { na Educação: problematizações sobre a homofobia } \\
\text { nas escolas. Brasília: Ministério da Educação, } \\
\text { Secretaria de Educação Continuada, Alfabetização e } \\
\text { Diversidade, UNESCO, 2009. }\end{array}$ \\
\hline & & $\begin{array}{l}\text { CARVALHO, Marília Pinto de. Mau aluno, boa aluna? } \\
\text { Como as professoras avaliam meninos e meninas. In.: } \\
\text { Revista Estudos Feministas. V.9.n.2. Florianópolis. } \\
2001 .\end{array}$ \\
\hline
\end{tabular}


FURLANI, Jimena. Educação Sexual na sala de aula. relações de gênero, orientação sexual e igualdade étnico-racial numa proposta de respeito às diferenças. Belo Horizonte: Autêntica, 2011.

Fonte: Conteúdo programático da referida disciplina, na Pós-Graduação stricto sensu.

Por meio do planejamento das aulas, percebemos que o tema homofobia fica evidente na aula cinco, no texto de Rios (2009); na aula seis, nos textos de Junqueira (2009) e Viñuales (2002); e na aula sete através da obra de Borrillo (2010). A partir da leitura desses textos, percebemos que cada autor, autora se utiliza de uma perspectiva construtivista ou desconstrutivista apontando como os sentidos hegemônicos e excludentes foram e ou são engendrados em processos históricos, contingenciais e tendo os sentidos reforçados por meio de distintas instituições. Destacamos ainda que mesmo os textos tendo em comum a perspectiva construtivista ou desconstrutivista, as autoras e os autores guardam suas especificidades por meio dos recortes de pesquisa quando analisam a homofobia e a lesbofobia. Também ressaltamos que esses textos serviram como parte do referencial teórico-metodológico adotado nesse artigo.

Nessa perspectiva, optamos em organizar a análise das abordagens de cada autor, autora, a partir dos sentidos construídos no percurso histórico sobre a homofobia até os sentidos que problematizam esse fenômeno na atualidade, ou seja, em seus aspectos diacrônico e sincrônico que condensam os sentidos nas referidas obras.

Sendo assim, percebe-se que na obra Homofobia: História e crítica de um preconceito, de Borrillo (2010), que é considerado referência no tema e que contribuiu significativamente para o avanço dos estudos sobre a homofobia, nos apresenta uma visão crítica sobre o processo histórico acerca do universo da homossexualidade e do surgimento do preconceito e da discriminação.

Alguns aspectos chamam nossa atenção, entre eles, como o pensamento cristão no processo histórico veio contribuindo significativamente para a condensação de sentido da homofobia que permanece e é constantemente reforçado hoje em dia. $O$ discurso religioso institui a dicotomia entre não pecadores e pecadores, que posteriormente foi reforçado pelo discurso da ciência sexual entre a heterossexualidade e a homossexualidade, e assim, entrelaçando todos os processos de construção da identidade de gênero e da orientação sexual entre normalidade e anormalidade. $O$ autor ressalta ainda que a Igreja foi a principal responsável pela criminalização das vivências, atualmente, denominadas, homossexuais, situação que favoreceu a adoção da mesma prática pelo Estado, pela ciência, pela família, pela escola e pela a mídia.

Todavia, nessa profícua obra, não foi abordada a questão de como a violência da Igbtfobia ganha dimensões muito mais difíceis de serem 
ultrapassadas ao se interseccionar com classe, raça-etnia, religiosidade, regionalidade e geração. É necessário compreender como as interseccionalidades reproduzem subalternidades nas estruturas sociais, nas representações simbólicas e nas subjetividades dos indivíduos (MATTOS, 2011).

Na obra de Rios (2009), intitulada: Homofobia na Perspectiva dos Direitos Humanos e no Contexto dos Estudos sobre Preconceito e Discriminação ressalta - quanto as manifestações homofóbicas ainda são negligenciadas em comparação com outras práticas discriminatórias e violentas. Ele define 0 conceito de homofobia como práticas preconceituosas e discriminatórias direcionadas para os homossexuais. Rios (2009) nos alerta para a impossibilidade que o termo tem de proporcionar visibilidade para as práticas de violência específicas como no caso da lesbofobia, da transfobia, entre outros. Assim, é problematizado a interseccionalidade entre corpo, gênero e sexualidade. Outro ponto destacado pelo autor é a invisibilidade que a homofobia, lesbofobia e transfobia assumem na sociedade atual. Tal invisibilidade, infelizmente, é decorrente da naturalização e de um argumento essencialista em que a heterossexualidade assume o status de normalidade.

Nessa perspectiva, Rios sublinha como a interseccionalidade pode contribuir para desmascarar e tornar visível a reprodução das estruturas e relações que subjugam os indivíduos em subalternidades. Tais violências podem culminar com a morte direta ou indiretamente desses indivíduos que intercruzam essas categorias.

Em Junqueira (2009), com seu estudo: Homofobia nas Escolas: um problema de todos, há uma convite para que os docentes reflitam se eles são cumplices da homofobia por meio de suas posturas em sala de aula de modo que se tenha consciência se estão sendo coniventes com as posturas homofóbicas e reproduzindo-as ou se essa violência é problematizada, desestabilizadas e desconstruídas por esses profissionais em processos educacionais de que priorizem o respeito pelo direito humano e o aprendizado com as diferenças. $O$ autor deixa evidente que a instituição escolar tem sido um espaço de reprodução social que na maioria das vezes legitima a violência contra homossexuais, seja quando induz indiretamente o aluno a essa prática ou quando silencia e finge que esse assunto não é competência da escola.

Junqueira (2009), ainda, problematiza a masculinidade hegemônica, pois essa masculinidade tóxica tem incentivado uma socialização dos meninos a agirem com violência apenas para se reafirmar. Assim, para ser considerado homem, precisa-se, a todo tempo, se opor aos homossexuais como pecaminosos, anormais, doentes, de modo que se possa afastar quaisquer aproximações que possa pôr a nossa masculinidade em "risco". 
Nesse aspecto, Junqueira (2009) ao mencionar a masculinidade hegemônica, sinaliza para a dimensão da interseccionalidade. A masculinidade hegemônica é constituída tendo como referência o indivíduo ser branco, homem, heterossexual e classe média ou alta. Assim, o sentido condensado sobre a masculinidade hegemônica necessita do outro colocado como subalterno, inferior, subjugado, "anormal", isto é, ser pobre, negro, homossexual (CONNELL; MESSERSCHMIDT; FERNANDES, 2013).

Por último, na obra de Viñuales (2002), Lesbofobia, é apresentada enquanto uma abordagem inovadora, quando destaca o fato que os indivíduos são sujeitos de desejos que muitas vezes buscam compreender as nuances da sexualidade apenas a partir do biológico, tornando a mente seu campo de batalha. A autora sublinha que houve a mudança de sentido e a possibilidade de desconstrução da anormalidade a partir da análise de Evelyn Hooker, quando consegue comprovar que a homossexualidade não pode ser considerada uma doença mental por falta de fundamentos científicos.

A referida autora ainda denuncia a invisibilidade da dupla violência que as mulheres sofrem quando são lésbicas por interseccionarem gênero e homossexualidade. Essa clivagem identitária entre gênero e sexualidade produz subalternidades e violências difíceis de serem ultrapassadas seja por essas pessoas que materializam a identidade lésbica ou por quaisquer pessoas que mesmo não sendo lésbicas possam ser categorizadas como tal. Ou seja, a lesbofobia determinando uma homogeneidade ficcional em que não há respeito para as diferenças mesmo que essas diferenças sejam entre as mulheres heterossexuais.

Entretanto, diante das obras das teóricas e dos teóricos utilizados, percebe-se a ausência de discussões sobre a diferença dos termos homofobia ou Igbtfobia ${ }^{5}$, pois como afirma Santos (2019), as pessoas que fazem parte do movimento LGBT e alguns pesquisadores já expõem o limite da impossibilidade do termo homofobia conseguir englobar e dar visibilidade à complexidade da violência sofrida pelos diversos grupos minoritários da comunidade LGBT, como exposto anteriormente.

Nessa perspectiva, Louro $(1997,2000)$ afirma que as relações de poder por meio da discursividade e dos dispositivos são capazes de instituir "verdades" e "normalidades" ao mesmo tempo que categorizam os corpos "anormais". A partir de uma estrutura machista, misógina, patriarcal, Igbtfóbica, há a denúncia

\footnotetext{
${ }^{5}$ Vale ressaltar para além das informações já explicitadas nesse artigo que a proposta de mudança do termo para Igbtfobia também foi sugerida pelos participantes da $3^{a}$ Conferência Nacional de Políticas Públicas de Direitos Humanos LGBT, em 2016. Os participantes propuseram que os órgãos do Estado passassem a adotar o termo Igbtfobia principalmente nas políticas públicas que objetivasse o enfrentamento das violências relacionadas ao referido público.
} 
de que os homens brancos, cisgêneros e heterossexuais são definidos como os corpos normais em detrimento dos corpos trans, "anormais" e abjetos como no caso do corpo feminino, transgênero, negro, indígena e gay e lésbico ao longo da história.

Nesse viés, o indivíduo de corpo, gênero ou sexualidade "disparatadas", visto inicialmente como pecador, com o passar dos anos passa a ser visto como se não fizesse parte dos humanos, ou seja, dependendo "da letra" que ele pertença na comunidade LGBT, o indivíduo passa de uma categoria sub-humana para um corpo abjeto, não humano como no caso das pessoas transexuais $\mathrm{e}$ transgêneros (BUTLER, 2003, 2008; LOURO, 2009; MIRANDA; LIMA, 2019).

\section{Considerações finais}

No estudo realizado ficou evidente, a preocupação que as docentes tiveram em abordar o percurso histórico da homofobia e lesbofobia, por meio do planejamento das aulas, dos debates e discussões sobre as obras que fizeram parte do corpus do nosso estudo. As referências, propostas na referida disciplina, apresentam a compreensão da homossexualidade desde a civilização grega e romana, passando pela forte influência do cristianismo até o surgimento da homofobia e sua manutenção nos dias atuais. Percebeu-se, ainda, a intenção em se incluir a temática da lesbofobia para marcar as especificidades da violência e da interseccionalidade entre gênero e sexualidade.

A partir da estruturação da disciplina e das teóricas e teóricos trabalhados, percebeu-se a capacidade que a educação possui em se tornar um dispositivo de desmistificação e desconstrução das concepções hegemônicas sobre a sexualidade. Quando se estuda o processo histórico e social da homofobia nos munimos de conhecimento e passamos a compreender quais são os determinantes desse fenômeno. Tal processo possibilita um posicionamento ético e político em favor da diversidade e da garantia de direitos humanos enquanto profissionais da educação e para uma sociedade mais democrática de respeito e aprendizado com a diferença. Santos e Santiago sinalizam para a importância das políticas públicas investirem na formação de professoras e professores para a prática pedagógica com gênero e sexualidades (2013)

Outro aspecto evidenciado nesse estudo diz respeito ao fato dos sentidos condensados nos textos possibilitarem o acesso a diferentes abordagens sobre a homofobia e lesbofobia e os desdobramentos desses temas com a interseccionalidade. Tal procedimento favorece o desenvolvimento de uma compreensão crítica acerca do fenômeno possibilitando desnaturalizar verdades absolutas ao mesmo tempo em que denuncia as violências sofridas nas clivagens identitárias.

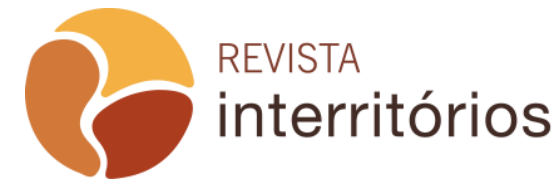

Interritórios | Revista de Educação Universidade Federal de Pernambuco, Caruaru, BRASIL | V.6 N.10 [2020] 
Destacamos que os textos possibilitaram discussões e reflexões numa perspectiva interseccional, no sentido de perceber as estruturas articuladas da opressão, que envolvem classe, raça, sexualidade e gênero. Além disso, os estudos acerca da homofobia, para além de abordar gênero e sexualidade, abarcaram o questionamento de visões de mundo, relações e concepções colonizadoras de sujeitos, sociedades e práticas. Portanto, as pesquisas documental e a bibliográfica revelam a abordagem interseccional presente na disciplina, a partir dos textos analisados.

Por fim, compreendemos que apesar dos avanços ocorridos em relação aos estudos e debates sobre a homofobia e a lesbofobia ao longo dos anos, consideramos que precisamos fomentar mais iniciativas que problematizem a violência LGBTfóbica com interseccionalidades para poderem ser trabalhadas tanto na formação inicial como na formação continuada nas universidades.

\section{REFERÊNCIAS}

AKOTIRENE, Carla. Interseccionalidade. São Paulo: Pólen, 2019.

ALBUQUERQUE JÚNIOR, Durval Muniz de. Nordestino: invenção do "falo" - uma história do gênero masculino (1920-1940). São Paulo: Intermédios, 2013.

BORRILLO, Daniel. Homofobia: História e crítica de um preconceito. Belo Horizonte: Editora Autêntica, 2010.

BUTLER, Judith. Problemas de gêneros: feminismo e subversão da identidade. Rio de Janeiro: Civilização Brasileira, 2003.

BUTLER, Judith. Cuerpos que importan: sobre lós limites materiales y discursivos Del "sexo". Buenos Aires, Barcelona, México: Paidós, 2008.

CONNELL, R. W; MESSERSCHMIDT, J. W.; FERNANDES, F. B. Martins. Masculinidade hegemônica: repensando o conceito. In: Estudos feministas p. 241282, 2013.

CRENSHAW, Kimberle W. A intersecionalidade na discriminação de raça e gênero. In: VV.AA. Cruzamento: raça e gênero. Brasília: Unifem, 2004. Disponível em: http://www.acaoeducativa.org.br/fdh/wp-content/uploads/2012/09/KimberleCrenshaw.pdf. Acessado em:15 de fevereiro de 2020.

DAVES, Angela. Mulheres, raça e classe. Tradução Heci Regina Candiani. São Paulo: Boitempo, 2016.

FANON, Frantz. Pele negra, máscaras brancas. Salvador: EDUFBA, 2008.

FOUCAULT, Michel. A Ordem do Discurso, São Paulo: Edições Loyola, 2004. 
FOUCAULT, Michel. História da sexualidade I: a vontade de saber. São Paulo:

Edições Graal, 2007.

GERHARDT, Tatiana Engel; SILVEIRA, Denise Tolfo (Org). Métodos de pesquisa.

Porto Alegre: Editora da UFRGS, 2009

GROSSI, Miriam Pillar, UZIEL, Anna Paula; MELLO, Luiz. Conjugalidades, parentalidades e identidades lésbicas, gays e travestis. Rio de Janeiro: Garamond, 2007.

HIRATA, Helena. Gênero, classe e raça Interseccionalidade e consubstancialidade das relações sociais. Tempo social. São Paulo, v. 26, n. 1, p. 61-73, June 2014 . Available from <http://www.scielo.br/scielo.php?script=sci_arttext\&pid=S0103$20702014000100005 \&$ Ing=en\&nrm=iso $>$.accesso 25 de fevereiro, 2020. https://doi.org/10.1590/S0103-20702014000100005.

JUNQUEIRA, Rogério Diniz. Homofobia nas Escolas: um problema de todos. In: JUNQUEIRA, Rogério Diniz (Org.). Diversidade Sexual na Educação:

problematizações sobre a homofobia nas escolas. Brasília, MEC/Unesco, 2009.

LAQUEUR, Thomas. Inventando o sexo. Rio de Janeiro: Relume Dumará, 2001.

LOURO, Guacira Lopes. Heteronormatividade e Homofobia. In: JUNQUEIRA, Rogério Diniz (Org.). Diversidade Sexual na Educação: problematizações sobre a homofobia nas escolas. Brasília, MEC/Unesco, 2009.

LUZ, Robenilton dos Santos. A intersecção dos conjuntos: gays e lésbicas negras em confronto com as hegemonias e sub-hegemonias. In Diversidade sexual e homofobia no Brasil. São Paulo: Perseu Abramo, 2011.

MATTOS, Patrícia. O conceito de interseccionalidade e suas vantagens para os estudos de gênero no Brasil. In: XV Congresso Brasileiro de Sociologia. grupo de trabalho Novas Sociologias: pesquisas interseccionais feministas, pós-coloniais e queer. Disponível em: http://www. sbsociologia. com. br/portal/index. php. 2011.

MELLO, Luiz. Novas famílias: conjugalidade homossexual no Brasil contemporâneo. Rio de Janeiro: Garamond, 2005.

MEMMI, Albert. Retrato do colonizado precedido pelo retrato do colonizador. São Paulo: Paz e Terra, 1989.

MIRANDA, M. H. Gonçalves. Mediações: telenovelas e sexualidades como elementos de condensações de sentidos híbridos entre a hegemonia e a resistência. In Razón y Palabra, V. 77, p. 01-17, 2011.

MIRANDA, M. H. Gonçalves. Percursos das transformações da teoria e da validação do conhecimento nas ciências humanas: do falsificacionismo de Popper à teoria de valor de Rickert. In Revista Interritórios, v. 2, p. 141-154, 2016.

MISKOLCI, R. A teoria queer e a questão das diferenças: por uma analítica da normalilzação. In: CONGRESSO DE LEITURA DO BRASIL, 16., 2007, Campinas. Anais... Campinas: Unicamp, 2007. Disponível em: 
http://alb.com.br/arquivo-morto/edicoes_anteriores/anais16/prog_pdf/prog03_01.pdf Acesso em: 01 de março de 2020.

MIRANDA, M. H. Gonçalves; ALENCAR, R. Do Essencialismo ao Desconstrutivismo: um breve balanço das pesquisas brasileiras sobre homossexualidade e suas interseções com as categorias de corpo e gênero. In Estudos de Sociologia, V. 1, p. 183-222, 2016.

MIRANDA, M. H. Gonçalves; LIMA, L. S. G. A. A Prática Pedagógica dos Direitos Humanos: marcadores sociais da diferença e o combate ao bullying. In Revista Momento-Diálogos em Educação, V. 28, p. 328-348, 2019.

RIOS, Roger Raupp. Homofobia na Perspectiva dos Direitos Humanos e no Contexto dos Estudos sobre Preconceito e Discriminação. In: JUNQUEIRA, Rogério Diniz (Org.). Diversidade Sexual na Educação: problematizações sobre a homofobia nas escolas. Brasília, MEC/Unesco, 2009, pp. 53-84.

SANTOS, Émerson Silva. Lgbtfobia na educação e a atuação da gestão escolar. Curitiba: Editora Appris, 2019.

SANTOS, Maria do Carmo Gonçalo; SANTIAGO, Maria Eliete. Políticas Curriculares, Formação de Professores/As e Diversidade. Atos De Pesquisa Em Educação Ppge/Me Issn 1809-0354 V. 8, n. 2, p.568-591, mai./ago. 2013 Disponível em: http://dx.doi.org/10.7867/1809-0354.2013v8n2p568-591 Acesso em 25 de março de 2020.

SANTOS, Maria do Carmo Gonçalo. As contribuições do currículo da formação para a prática pedagógica com gênero e sexualidade na educação básica. Tese (Doutorado em Educação). Universidade Federal de Pernambuco, CE. Programa de Pós-Graduação em Educação, 2016. 400fl

SIQUEIRA, Elton B. Soares de; MIRANDA, Marcelo H. Gonçalves. A Experiência estética e desestabilizações das masculinidades no teatro brasileiro moderno e contemporâneo. In (Orgs.) CAETANO, Marcio; SILVA JUNIOR, Paulo Melgaço. De Guri a Cabra-macho: masculinidades no Brasil. Rio de Janeiro: Lamparina, 2018.

UZIEL, Anna Paula. Homossexualidade e adoção. Rio de Janeiro: Garamond, 2007. VIÑUALES, Olga. Lesbofobia. Barcelona: Edicions Bellaterra, 2002. 